\title{
Study on the Four Critically III Score Methods of Newborns Critically III
}

\author{
Cui Liu ${ }^{1}$, Tao $\mathrm{Li}^{1}, \mathrm{Yu} \mathrm{Fu}^{2}$, Chao Zeng ${ }^{1}, \mathrm{Yi} \mathrm{Li}^{1}$ \\ ${ }^{1}$ Hubei Medical College, Shiyan, Hubei, 442000 \\ ${ }^{2}$ People's Hospital of Hubei Medical College, Shiyan, Hubei, 442000 \\ 346591653@163.com
}

KEYWORDS: Critical Score; Death; Moderate to Severe HIE; Mechanical Ventilation; TRIPS

\begin{abstract}
Objective: To investigate the NCIS, TRIPS, SNAP-II, research SNAPPE- II score four critically ill newborns and assess the predictive accuracy of superiority. Methods: The clinical data were collected in 2015, People's Hospital Neonatal Intensive Care Unit of Hubei Medical College prospective study comparing four score of death, III degree of intracranial hemorrhage, moderate to severe HIE, mechanical ventilation, sepsis, oxygen supply $>21 \mathrm{~d}$, feeding intolerance $>$ 7d, hospitalization time $>28 \mathrm{~d}$, three blood transfusions nine kinds of critically ill newborns, and to assess the predictive accuracy of the superiority of its incidence. Results: 480 newborns included in the study. H-L goodness of fit test shows four kinds of scoring models have a better fit $(\mathrm{P}>0.05), \mathrm{P}$ values were $0.53,0.68,0.92,0.94$. Analysis of nine kinds were critical illness occurs, the area (AUC) under the receiver operating characteristic curves were four score $>0.5$; wherein Death, moderate to severe HIE, the higher the accuracy of prediction of mechanical ventilation, AUC was> 0.8. TRIPS and SNAPPE- II highest prediction accuracy of the above three critically ill newborns. Conclusion: TRIPS and SNAPPE- II has high neonatal mortality, moderate to severe HIE, the predictive accuracy of mechanical ventilation, can be applied in clinical practice. TRIPS score simple, quick access, it can promote the use of foundation hospitals.
\end{abstract}

\section{Introduction}

With the rapid development of neonatal emergency medicine level NICU (Neonatal Intensive Care Unit, NICU) increasing levels of health care, the neonatal mortality rate of annual decline. Currently the treatment of critically ill newborns NICU has become the focus of hospitalized newborns as timely and accurate assessment, prediction of risk of the occurrence of critical illness, death, positive and effective early interventions hospitalization, can to a large extent on improving the prognosis, on the other hand help the doctor-patient communication, reduce hidden medical disputes.

European countries currently commonly used scoring methods are: neonatal transport physiological stability index (Transport Risk Index of Physiologic Stability, TRIPS), neonatal acute physiology score -II (Score for Neonatal Acute Physiology version II, SNAP-II), perinatal-neonatal acute physiology score - II (score for neonatal acute Physiology, Perinatal Extension, Version II, SNAPPE- II ) ,. Domestic neonatal scoring a late start, is commonly used in neonatal critical illness score (Neonatal Critial Illness Score, NCIS), because many projects score achieved score takes time, use up more trouble. The study on the method to predict the score of the four common critically ill newborns were compared to find the most simple and effective method used in clinical practice. 


\section{Materials and Methods}

\section{A. Study Objects}

Prospective study is to collect clinical data People's Hospital Neonatal Intensive Care Unit of January 1, 2005 to December 31, 2015 in Hubei Medical College. Inclusion criteria: within 24 hours after birth Check NICU newborns. Exclusion criteria: (1) less than 24 hours of admission or discharge death cases; (2) severe congenital malformations.

\section{B. Scoring Methods and Diagnostic Criteria}

(1)NCIS reference rates in 2001 to develop neonatal critical illness scoring system (draft), including severity score and individual indicators in two parts, the two parts of the cross, this experiment only study score portion 11 OUTCOME MEASURES: heart rate, systolic pressure, breathing, $\mathrm{PaO} 2, \mathrm{pH}$, sodium, potassium, creatinine, urea nitrogen, hematocrit, gastrointestinal manifestations, available 24 hours after admission. Its value ranges from 0 to 100 points, the lower the score the more severe the disease, $\leqslant 90$ into critical, score $>90$ is divided into non-critical.

(2)TRIPS rates 4 OUTCOME MEASURES: body temperature, respiratory status, systolic blood pressure, response to stimuli, obtained one hour after admission. Its score ranges from 0 to 65 points, the higher the score, the more severe the disease, the score $\geqslant 20$ into critical; $<20$ divided into non-critical.

(3)SNAP-II score 6 OUTCOME MEASURES: mean arterial pressure, low body temperature, $\mathrm{PaO} 2$ / FiO2 ratio, $\mathrm{pH}$, recurrent seizures, urine within 12 hours after admission, obtained 12 hours after admission. Its score ranges from 0 to 115 points, the higher the score, the more severe the disease, the score $\geqslant 10$ into critical; $<10$ divided into non-critical.

(4)SNAPPE- II score 9 OUTCOME MEASURES: mean arterial pressure, low body temperature, $\mathrm{PaO} 2 / \mathrm{FiO} 2$ ratio, $\mathrm{pH}$, recurrent seizures within 12 hours after admission urine output, low birth weight, 5 min Apgar scores, gestational age children, obtained 12 hours after admission. Its score ranges from 0 to 165 points, the higher the score, the more severe the disease, the score $\geqslant 10$ into critical; $<10$ divided into non-critical.

Feeding intolerance: (1) appear repeatedly vomiting after feeding; (2) gastric residual volume of more than $30 \%$ of the amount of feed; (3) bloating; (4) stomach with coffee-like material; (5) the second weekend feeding amount $<8 \mathrm{ml} /$ ( $\mathrm{kg}$ - times ); (6) were fasted $>2$ times.

Mechanical ventilation: the need for non-invasive mechanical ventilation or endotracheal intubation mechanical ventilation.

\section{Research Methods}

Gestational age, corrected gestational age, birth weight, gender, mode of delivery, Apgar score, antenatal use of hormones, blood cord blood. Admission: basic vital signs, convulsions, blood gas analysis, laboratory tests index, blood culture, ventilator, oxygen therapy, the gastrointestinal tract (including feeding case), severe infection, blood transfusions, intracranial hemorrhage, hospital stay, prognosis .

All those who were included in the four scores were relatively neonatal death, III degree of intracranial hemorrhage, moderate to severe hypoxic-ischemic encephalopathy (Hypoxic ischemic encephalopathy, HIE), mechanical ventilation, sepsis, oxygen time $>21 \mathrm{~d}$, feeding intolerance $>7 \mathrm{~d}$, hospitalization time $>28 \mathrm{~d}$, when three blood transfusions in critically ill patients, the superiority of the four score and evaluation of forecast accuracy.

Measurement data using () expression, the expression rate of count data, hypothesis testing using $\mathrm{t}$ test, $\mathrm{x} 2$ test, test level $\alpha=0.05$. Statistical data using SPSS13.0 software. Receiver operating characteristic curve (Receiver Operating Curve, ROC) and the area under the curve (ROC Area, 
AUC) to assess the predictive accuracy: AUC $<0.5$ Tips prediction accuracy is poor, $>0.8$ prediction accuracy.

\section{Result}

\section{A. General Information Case}

420 cases included in the study were male and 207 cases (49.3\%), female 213 cases (50.7\%). The average gestational age (34.27 \pm 3.41$)$ weeks, average birth weight $(2.19 \pm 0.63) \mathrm{Kg}$, average length of stay $(17.21 \pm 12.76)$ d. 18 deaths (4.29\%), III degree of intracranial hemorrhage in 33 cases $(7.86 \%)$, moderate to severe HIE in 33 cases (7.86\%), mechanical ventilation in 84 cases (25.0\%), sepsis in 36 cases (8.57\%), oxygen time $>21 \mathrm{~d}$ in 42 cases (10.0\%), feeding intolerance $>7 \mathrm{~d} 96$ cases $(22.86 \%)$, hospitalization time $>28 \mathrm{~d} 78$ cases $(18.57 \%)$, three blood transfusions in 72 cases (17.14\%).

\section{B. Four Kinds of Prediction Score ROC Curve Analysis}

Four kinds of scoring for nine critically ill patients have better predictability, and the difference was statistically significant five $(\mathrm{P}>0.05)$. But its death, moderate to severe HIE, high mechanical ventilation forecasting accuracy, which AUC $>0.8$, the results in Table1

Table 1 . The area under the ROC curve occurs nine kinds of critically ill patients (AUC)

\begin{tabular}{|c|c|c|c|c|c|}
\hline Critical Ill & $\begin{array}{c}\text { NCIS } \\
(95 \% \mathrm{CI})\end{array}$ & $\begin{array}{c}\text { TRIPS } \\
(95 \% \mathrm{CI})\end{array}$ & $\begin{array}{l}\text { SNAP-II } \\
(95 \% \mathrm{CI})\end{array}$ & $\begin{array}{c}\text { SNAPPE- II } \\
(95 \% \mathrm{CI})\end{array}$ & $P$ \\
\hline Death & $\begin{array}{c}0.806 \\
(0.483,0.930)\end{array}$ & $\begin{array}{c}0.833 \\
(0.508,0.957)\end{array}$ & $\begin{array}{c}0.804 \\
(0.514,0.894)\end{array}$ & $\begin{array}{c}0.839 \\
(0.605,0.873)\end{array}$ & 0.818 \\
\hline $\begin{array}{l}\text { III degree of } \\
\text { intracranial }\end{array}$ & $\begin{array}{c}0.550 \\
(0.367,0.733)\end{array}$ & $\begin{array}{c}0.558 \\
(0.374,0.742)\end{array}$ & $\begin{array}{c}0.577 \\
(0.391,0.763)\end{array}$ & $\begin{array}{c}0.654 \\
(0.492,0.817)\end{array}$ & 0.537 \\
\hline hemorrhage & $\begin{array}{c}0.806 \\
(0.633,0.777)\end{array}$ & $\begin{array}{c}0.898 \\
(0.627,0.870)\end{array}$ & $\begin{array}{c}0.818 \\
(0.635,0.715)\end{array}$ & $\begin{array}{c}0.835 \\
(0.651,0.772)\end{array}$ & 0.452 \\
\hline Moderate to & & & & & \\
\hline severe HIE & $\begin{array}{c}0.840 \\
(0.618,0.785)\end{array}$ & $\begin{array}{c}0.852 \\
(0.631,0.773)\end{array}$ & $\begin{array}{c}0.831 \\
(0.608,0.755)\end{array}$ & $\begin{array}{c}0.865 \\
(0.646,0.875)\end{array}$ & 0.211 \\
\hline Mechanical & & & & & \\
\hline $\begin{array}{l}\text { ventilation } \\
\text { septicemia }\end{array}$ & $\begin{array}{c}0.543 \\
(0.282,0.604)\end{array}$ & $\begin{array}{c}0.551 \\
(0.288,0.613)\end{array}$ & $\begin{array}{c}0.570 \\
(0.304,0.636)\end{array}$ & $\begin{array}{c}0.577 \\
(0.305,0.648)\end{array}$ & 0.325 \\
\hline $\begin{array}{l}\text { Oxygen } \\
\text { time> 21d } \\
\text { Feeding }\end{array}$ & $\begin{array}{c}0.548 \\
(0.384,0.711)\end{array}$ & $\begin{array}{c}0.556 \\
(0.391,0.720)\end{array}$ & $\begin{array}{c}0.575 \\
(0.409,0.742)\end{array}$ & $\begin{array}{c}0.635 \\
(0.414,0.761)\end{array}$ & 0.188 \\
\hline $\begin{array}{c}\text { intolerance }> \\
7 d\end{array}$ & $\begin{array}{c}0.648 \\
(0.533,0.763)\end{array}$ & $\begin{array}{c}0.657 \\
(0.543,0.772)\end{array}$ & $\begin{array}{c}0.600 \\
(0.482,0.717)\end{array}$ & $\begin{array}{c}0.537 \\
(0.423,0.651)\end{array}$ & 0.158 \\
\hline Hospitalizati & & & & & \\
\hline $\begin{array}{c}\text { on time }> \\
28 \mathrm{~d}\end{array}$ & $\begin{array}{c}0.570 \\
(0.443,0.696)\end{array}$ & $\begin{array}{c}0.555 \\
(0.429,0.681)\end{array}$ & $\begin{array}{c}0.600 \\
(0.473,0.728)\end{array}$ & $\begin{array}{c}0.512 \\
(0.387,0.650)\end{array}$ & 0.101 \\
\hline Three blood & & & & & \\
\hline
\end{tabular}




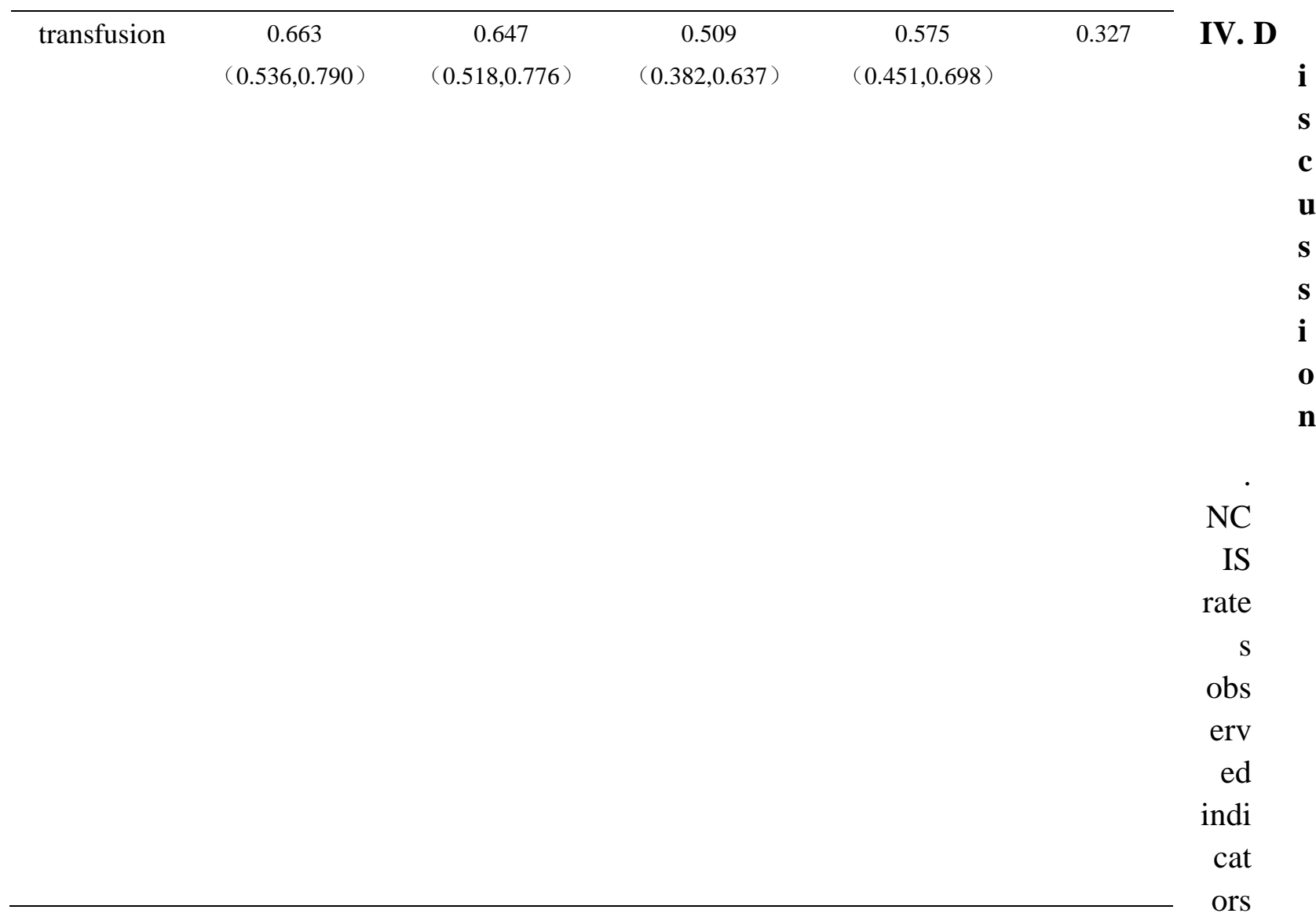

11, in addition to admission vital signs, but also the need to obtain blood and blood chemistry results, in order to obtain, before being drawn 12-24 hours after admission score, the more complicated and delayed. TRIPS Rating outcome measures 4 by physical examination and measurement of vital signs available, a few minutes after admission rates, easily and quickly, and the hospital no hardware requirements, application and wards, clinics, transport and primary hospital. SNAP-II and SNAPPE- II score observed indicators 6, the need to obtain the results of blood collected $12 \mathrm{~h}$ urine, obtained 12 hours after admission rates, no blood gas equipment hospitals can not expand. In summary SNAP-II and SNAPPE- II score required in order to carry out the flesh hospital equipment; NCIS ratings need to obtain the results of blood biochemistry; TRIPS rates from hospital equipment and environmental constraints, the score quickly and easily.

Four score prediction III degree of intracranial hemorrhage, sepsis, oxygen time $>21 \mathrm{~d}$, feeding intolerance $>7 \mathrm{~d}$, hospitalization time $>28 \mathrm{~d}$, three times the transfusion therapy in critically ill patients AUC was> 0.5, the sensitivity and specificity were higher, indicating it can also be used to predict these six critically ill. Some scholars use to predict neonatal critical score of other diseases, hospitalization time. Dammann O and other studies have found that SNAP- II and SNAPPE- II certain extent, predictable long-term neonatal nervous system disorders, such as cerebral palsy, vision and hearing disorders. Study Sundaram V and other scholars found that, NICU septicemia in children SNAP- II > $40 \mathrm{~min}$, the incidence of multiple organ dysfunction and death increased significantly, neonatal sepsis mortality forecast is high. Kling PJ and other studies have found, so SNAP- II score predicted neonatal NICU length of stay is greater than 21 days. Another report SNAP-II can help predict hyaline membrane disease occurs. Huang Yuan-ying Study and other scholars show SNAP- II score were there for the first time and length of hospital stay and NCIS correlation, SNAP- II can be used to assess the level of medical institutions within the NICU, it can also be used between different NICU levels of medical institutions to compare. 


\section{Conclusion}

In summary the four score can predict neonatal critical care, TRIPS and SNAPPE- II predict death, moderate to severe HIE, mechanical ventilation, highest accuracy, SNAPPE- II apply to hospital blood gas analysis can be carried out, TRIPS Rating simple, rapid, and high accuracy, can be used for clinics, wards, transport and hospital, the newborn determine whether to enter the NICU treatment, a preliminary assessment of the condition and prognosis in clinical work. But the sample size for the study table below normal, selected only children's hospital as an object of study, further research on this aspect of the case to support the need for greater capacity and more like the center of the table.

\section{REFERENCE:}

[1] Dammann O,Shah B, Naples M,et al. Interinstitutional variation in prediction of death by SNAP- II and SNAPPE- II among extremely preterm infants[J]. Pediatrics,2009,124(5): 1001-1006.

[2] Shelley Reid, Barbara Bajuk, Kei Lui,et al.Comparing CRIB-II and SNAPPE-II as mortality predictors for very preterm infants[J]. Journal of Paediatrics and Child Health,2014,8:1-5.

[3]Berry MA, Shah PS, Brouillette RT,e t al. Predictors of mortality and length of stay forneonates admitted to children' s hospital neonatal intensive care[J]. Units Journal of perinatology,2008,28(4): 297-302.

[4]Suksham J, Anuradha B.SNAPPE-- II score for predicting mortality in a level neonatal intensive care unit[J]. Dicle Medical Journal,2009,36(4):333-335.

[5]Shoo K. Lee, MBBS, FRCPC, et al. Transport Risk Index of Physiologic Stability, Version II (TRIPS-II): A Simple and Practical Neonatal Illness Severity Score[J].Am J Perinatol, 2013, 30:395-400.

[6]Dammann O, Naples M, Bednarek F, et al. SNAP- II and SNAPPE- II and the risk of and functional brain disorders in extremely low gestational age newborns: the ELGAN study[J]. Neonatology,2010,97(2): 71-82.

[7]Sundaram V, Dutta S, Ahlawalia J, et al. Score for neonatal acute physiology predicts mortality and persistent organ dysfunction in neonates with severe septicemia[J].Indian pediatric,2009,46(9):775-780.

[8]Kling PJ, Sullivan TM, Leftwich ME, et al. Score for neonatal acute physiology and phlebotomy blood loss predict erythrocyte transfusions in premature infants[J]. Arch Pediatr \& Adolescent Medicine, 1997, 151(1) :151-154.

[9]Ma XL, Xu XF, Chen C, et al. Epidemiology of respiratory distress and the illness severity in late preterm or term infants: a prospective multi-center study[J]. Chin Med J, 2010, 